\title{
Malignant Tonsillar Neoplasm
}

National Cancer Institute

\section{Source}

National Cancer Institute. Malignant Tonsillar Neoplasm. NCI Thesaurus. Code C7404.

A primary or metastatic malignant neoplasm that affects the tonsil. 